\title{
Comparación de ciberacoso y autoeficacia en redes sociales: Ciudad de México y Estado de México
}

\section{Comparison of cyberbullying and self-efficacy in social networks: Mexico City and the State of Mexico}

\author{
Sandra I. Muñoz-Maldonado, Verónica Piña-Pazarán, Ximena Durán-Baca y \\ Consuelo R. Rosales-Piña \\ Universidad Nacional Autónoma de México
}

\begin{abstract}
Resumen
El objetivo del presente estudio fue comparar la frecuencia con la que se presenta el ciberacoso, el tipo de respuestas ante él, así como el conocimiento y autoeficacia para el uso de redes sociales en jóvenes de la Ciudad de México y del Estado de México. La muestra estuvo constituida por 1673 alumnos de ambos sexos (862 de la Ciudad de México y 811 del Estado de México) de entre 14 y 20 años. Se realizaron análisis de frecuencias y la prueba $x 2$. Los resultados mostraron diferencias significativas entre la frecuencia en la que se presentó el ciberacoso y los conocimientos que poseen los jóvenes entre las dos entidades federativas, siendo más elevado en la Ciudad de México en comparación con el Estado de México. Sin embargo, en la forma en que los jóvenes responden al ciberacoso (asertiva y empática) y en autoeficacia la diferencia es contraria, es decir, el Estado de México puntúa mayor que la Ciudad de México. Finalmente, se concluye que se deben realizar más investigaciones de esta índole debido a que existe una escasa información acerca del ciberacoso en México.
\end{abstract}

\begin{abstract}
The objective of this study was to compare the frequency of cyberbullying, the type of responses to it, as well as knowledge and self-efficacy in the use of social networks in young people from Mexico City and the State of Mexico. The sample comprised 1673 students of both sexes between 14 and 20 years old (862 participants from Mexico City and 811 from the State of Mexico). We performed descriptive analyses and X2 tests. The results showed a significant difference between the frequency of cyberbullying and the level of young people's knowledge. The latter variable was higher in Mexico City than in the State of Mexico. However, participants from the State of Mexico scored higher than those from Mexico City in the way they respond to cyberbullying (assertive and empathetic) and in self-efficacy. More research on this issue is needed given the scarcity of statistics and information on this topic in Mexico.
\end{abstract}

Key words: Cyberbullying, self-efficacy, social networks, empathy, assertiveness.

Palabras clave: Ciberacoso, autoeficacia, redes sociales, empatía, asertividad.

Cómo citar este artículo: Muñoz-Maldonado, S. I., Piña-Pazarán, V., Durán-Baca, X., \& Rosales-Piña, C. R. (2021). Comparación de ciberacoso y autoeficacia en redes sociales: Ciudad de México y Estado de México. Escritos de Psicología - Psychological Writings, 14(1), 11-19. https://doi.org.10.24310/espsiescpsi.v14i1.12688

Correspondencia: Sandra I. Muñoz-Maldonado, Avenida de los Barrios, $n^{0} 1$, Torre de Tutorías Cubículo 20. Colonia Los Reyes Ixtacala, Tlalnepantla, Estado de México, México, C.P. 54090. sandra.munoz@iztacala.unam.m Coautora Verónica Piña-Pazarán, psicologaveronica2019@gmail.com. Coautora Ximena Durán-Baca, dbximena@hotmail.com. Coautora, Consuelo R. Rosales-Piña, rubi.rosales@iztacala.unam.mx 


\section{Introducción}

El ciberacoso es el conjunto de comportamientos constantes, reiterados y deliberados, que se realizan con el objetivo de agredir a iguales o coetáneos y que se llevan a cabo a través de medios electrónicos de comunicación como son las redes sociales o aplicaciones de mensajería instantánea que tienen la particularidad de la inmediatez y la amplia difusión. Por lo regular, la agresión se produce hacia una persona que se percibe con dificultades para defenderse; es decir, existe un desequilibrio de poder entre la persona que agrede y la persona agredida (Arab \& Díaz, 2014; Buelga \& Pons, 2012; Buelga et al., 2015; Li, 2008; Oliveros et al., 2012; Patchin \& Hinduja, 2006).

En el proceoso del ciberacoso se identifican tres papeles importantes, el primero es el de acosador o bullie, el que ejerce daño; el segundo, el de la víctima que recibe el maltrato; y el tercero le corresponde a los testigos: los que observan cómo se da la agresión o la difunden. Estos espectadores son un pilar importante para que se lleve a cabo la difusión y expansión de dicho material de ofensa; sin ellos el ciberacoso no tendría un grave y extenso impacto (Garaigordobil \& Aliri, 2013). Oliveros et al. (2012) mencionan que el ciberacoso puede realizarse de distintas formas: mediante la publicación de imágenes, videos o textos con la intención de burlarse, humillar o esparcir un rumor; también por la insistencia del envío de mensajes desagradables, la denigración usando imágenes o textos, el robo de identidad en redes sociales, la exclusión de grupos virtuales o la intimidación a través de mensajes. El ciberacoso se suele presentar asociado al acoso escolar en el aula. Un estudio realizado por Cardozo et al. (2017) indica que un 54\% de los estudiantes reporta acoso escolar presencial en, al menos, tres ocasiones y un $37 \%$ ciberacoso en la misma frecuencia, de tal forma que ambas modalidades se pueden presentar al mismo tiempo.

Estos comportamientos traen consigo consecuencias negativas principalmente a aquellos que lo sufren, ya que viven en constante amenaza de violencia que con el paso del tiempo produce estragos en forma de problemas psicológicos y sociales: pérdida de confianza, baja autoestima, depresión, ira, frustración o auto denigración, aislamiento social y discriminación (Patchin \& Hinduja, 2006). La investigación sobre ciberacoso además de determinar las consecuencias asociadas a este fenómeno (García-Maldonado et al., 2011) se ha centrado en identificar qué otros aspectos psicológicos o sociales se asocian con la presencia de este comportamiento agresivo. Algunos de estos elementos se describen a continuación.

La facilidad en el acceso a las redes sociales ha traído consigo condiciones no favorables que ponen en riesgo a los adolescentes; por ejemplo, se puede acceder a redes sociales e internet sin una debida supervisión, no se verifica la identidad de la persona al crear una cuenta, y se añaden amigos al perfil sin necesidad de tener una interacción cara a cara (Espinar \& González, 2009). Existe una ausencia de monitorización de los menores por sus padres, una falta de información acerca de las condiciones de uso y privacidad de las diferentes redes sociales, y una potencial complicación al producirse una adicción a este tipo de aplicaciones (Lee et al., 2017).

Un aspecto que se encuentra ampliamente relacionado con la aparición de conductas de riesgo en medios electrónicos es el pobre manejo de la privacidad y seguridad, ya que se ha identificado que aquellos jóvenes que no cuidan estos aspectos son más propensos a sufrir ciberacoso y, también, extorsión sexual y grooming (definido como engaño pederasta por internet o acoso a un menor por parte de un adulto con un contenido sexual explícito o implícito) (Finkelhor et al., 2021).

Otro factor asociado es la autoeficacia en el uso de internet (Lee et al., 2017): quienes presentan deficiencias en el conocimiento y manejo de internet se perciben como menos autoeficaces para proteger sus datos y privacidad, mientras que aquellos que se muestran confiados en sus habilidades en internet tienden a ser más autoeficaces en el manejo de su privacidad y datos. Es por ello que es de gran importancia que los jóvenes tengan conocimientos necesarios sobre el uso de redes sociales y sobre la navegación en sitios web, pues cuanto más informados estén mejor podrán proteger sus datos y privacidad.

Finalmente, se debe considerar la forma en que se emplean las redes para la comunicación. Existen diferentes formas de transmitir un mensaje, de forma agresiva, pasiva o asertiva, siendo esta última la más adecuada porque se consideran los sentimientos y emociones al expresarse pensando cómo el mensaje afectará al receptor del mismo (Briones \& Ortiz, 2014). Cuando predomina una comunicación agresiva hay mayor probabilidad de altercados (Corrales et al., 2017) fomentando un ambiente poco favorable de interacción. Garaigordobil (2017) menciona que los jóvenes que suelen convivir de forma agresiva o resolver situaciones sociales de la misma manera, son más propensos a situaciones de acoso y ciberacoso. 
En los últimos años se ha reportado un aumento en las cifras de ciberacoso en la mayoría de los países, probablemente debido al hecho de que en la actualidad existe un mayor acceso a la tecnología y por ende un mayor manejo de teléfonos inteligentes (Livingstone et al., 2016). La Organización para la Cooperación y el Desarrollo Económicos, OCDE por sus siglas en español, afirma que un $20 \%$ de estudiantes en México declararon haber sufrido acoso escolar algunas veces en el último mes antes de la encuesta, porcentaje similar a la media general reportada para todos los países evaluados que es de 19\% (OCDE, 2017). En una encuesta de ciberacoso en México realizada por el Instituto Nacional de Estadística, Geografía e Informática (INEGI, 2017), se identifica la prevalencia de ciberacoso por roles donde se reporta que un $16.2 \%$ han sido víctimas, $49.38 \%$ agresores y $2.95 \%$ espectadores de situaciones de ciberacoso. Se menciona a Tabasco como el estado con mayor prevalencia de ciberacoso con $22.1 \%$, seguido de Veracruz $(21.8 \%)$ y Zacatecas $(21.4 \%)$, mientras que la Ciudad de México presenta un $16.8 \%$ y el Estado de México $14.7 \%$, estas dos últimas entidades son las que mayor densidad de población tienen (INEGI, 2017).

Lo expuesto hasta ahora evidencia la necesidad de seguir estudiando la prevalencia del fenómeno en México, por lo que sería un buen inicio la realización de estudios en las entidades federativas más pobladas y en desarrollo, que si bien se encuentran cercanas geográficamente las separan leyes, desarrollo, posibilidades y sería interesante conocer si comparten o difieren en la prevalencia de ciberacoso.

Es así que el objetivo principal de esta investigación es comparar la frecuencia en la que se presenta el ciberacoso, el tipo de respuestas ante él, el conocimiento y autoeficacia para el uso de redes sociales en jóvenes de la Ciudad de México y Estado de México. Como objetivos particulares se pretende, en primer lugar, evaluar el nivel de autoeficacia y el nivel de conocimiento que perciben en el manejo de la privacidad y seguridad de redes sociales en alumnos del Estado de México y Ciudad de México; en segundo lugar, identificar si existen diferencias en las respuestas asertivas, agresivas, pasivas y empáticas que dan los adolescentes de la Ciudad de México y Estado de México ante situaciones de ciberacoso.

\section{Participantes}

\section{Método}

Los participantes fueron 1,673 alumnos de entre 14 y 20 años aproximadamente, de escuelas públicas de educación media superior, de tres principales instituciones: Centros de Estudios Tecnológico Industrial y de Servicios (CETIS), Centros de Bachillerato Tecnológico Industrial y de Servicio (CBTIS) y Escuelas Preparatorias Oficiales (EPO). 29 de ellas se encontraban ubicadas en la Ciudad de México y 15 en el Estado de México. El tipo de muestreo fue probabilístico de estrato (Hernández et al., 2010); es decir, que de una población inicial de 38,842 estudiantes se extrajeron dos segmentos los cuales pertenecían a la Ciudad y el Estado de México, de donde se obtuvo un nuevo estrato de 400 hombres y 462 mujeres de Ciudad de México y 405 hombres y 406 mujeres del Estado de México, resultando así la muestra total.

El estudio fue de tipo descriptivo y comparativo debido a que busca describir propiedades, características y rasgos de dos diferentes muestras, explorando cómo se manifiesta el fenómeno estudiado. Se trata de un diseño no experimental debido a que no se manipularon ni controlaron variables y de tipo transversal, ya que sólo se aplicó una evaluación (Hernández et al., 2010).

\section{Instrumento}

Se realizó de forma expresa para la investigación una encuesta conformada por 15 ítems con respuestas de frecuencia con valores de 0 a 4, dónde 0 equivalía a nunca, 1 a pocas veces, 2 a algunas veces, 3 a muchas veces y 4 a siempre; los primeros seis ítems diagnosticaban la frecuencia de los tres roles de ciberacoso, los siguientes seis el conocimiento acerca de la privacidad y seguridad en redes sociales y tres más determinaban la autoeficacia con la que se percibían para el manejo de las redes.

Además, se incluyeron dos viñetas que valoraban la respuesta ante situaciones de ciberacoso, la primera de ellas consistía en la existencia hipotética de un video vergonzoso de alguno de sus compañeros en alguna plataforma virtual del grupo, publicado por algún miembro de este. Se pedía que respondiera conforme a tres tipos de respuesta, de forma agresiva, pasiva o asertiva. En la segunda viñeta se planteaba la situación en la que muchos compañeros habían compartido el video, por lo que casi toda la escuela estaba enterada de lo que había sucedido llevando a burlas y risas hacia el compañero que aparecía en el video, cuestionando así la forma en que se reaccionaría ante su compañero. Las respuestas reflejaban un comportamiento agresivo, pasivo o empático. 


\section{Procedimiento}

Se asistió a cada una de las escuelas preparatorias a solicitar el permiso para realizar una evaluación, se entregó a los estudiantes un consentimiento informado con la autorización para participar, y se agendó fecha, hora y lugar en donde se llevaría a cabo la aplicación de los cuestionarios. El día agendado se llegó al aula habilitada con tabletas suficientes para los alumnos, los cuales iban pasando con su respectivo grupo, se les dieron instrucciones de leer detenidamente y contestar conforme lo demandaban las preguntas, es decir que en los primeros 15 ítems según una escala Likert (de 0 a 4 ) y en los dos últimos ítems debían responder a las opciones a, b ó c. Se disponía de 15 minutos para responder. Para la solución de cualquier duda bastaba con levantar la mano para que los encargados acudieran a su lugar a resolverla. A medida que los alumnos iban respondiendo, las respuestas se iban guardando automáticamente en el formulario.

\section{Análisis de datos}

El análisis de datos se realizó con el programa estadístico IBM SPSS. Inicialmente se realizó una reorganización de las respuestas de la encuesta, se reagruparon para poder tener tres categorías: nunca $(0)$, algunas veces $(1,2)$ y muchas veces $(3,4)$. Se realizó un análisis de frecuencias con la finalidad de contabilizar las respuestas en cada uno de los ítems. Para las viñetas se realizó también un análisis de frecuencias. Para comparar las frecuencias entre la Ciudad de México y el Estado de México se empleó una prueba de chi-cuadrado.

\section{Resultados}

En las Tablas 1 y 2 se presenta el análisis de frecuencias de respuesta de la muestra total en los ítems que conforman la encuesta y las viñetas, respectivamente. En la Tabla 3 se muestra el porcentaje obtenido en las muestras de la Ciudad de México y del Estado de México respecto a las variables evaluadas.

En la muestra general se identificó la proporción de participantes que han ejercido alguno de los roles. Respecto al rol de testigo, se encontró que el $15.4 \%$ de los jóvenes nunca ha sido testigos de que molesten a sus compañeros, mientras que el $63.1 \%$ y $21.5 \%$ manifiesta que sí lo ha sido algunas o muchas veces, respectivamente. Un $37.9 \%$ de ellos reporta que nunca ha visto cómo sus compañeros utilizan las redes sociales para molestar a otros. En el rol de víctima se identifica una proporción baja de jóvenes que reporta que muchas veces se han burlado de ellos por su apariencia o han sido atacados por medio de redes sociales con un $10.6 \%$ y un $7.7 \%$, respectivamente. En el rol de bullie, se identifica también una pequeña proporción que sí han molestado muchas veces a sus compañeros $(9.3 \%)$ o han subido imágenes en plataformas sociales con el fin de burlarse (8\%). De forma general, se puede observar que la proporción de bullies y víctimas es similar, y que los testigos son casi el doble de participantes que lo han observado de manera constante o continua (Ver Tabla 1).

Respecto a la dimensión de conocimiento sobre el uso de las redes, la privacidad y seguridad, un $31.6 \%$ de los jóvenes nunca ha consultado las reglas comunitarias de las redes sociales, un $13 \%$ de los participantes nunca ha utilizado la configuración de privacidad en plataformas sociales, y un $32.4 \%$ no ha buscado información sobre prevención de bullying (Tabla 1).

Un aspecto importante es que la mitad de los participantes nunca han reportado publicaciones ofensivas y tan solo el $16 \%$ lo ha hecho. Sobre la información en la comunidad de ayuda, un $18.7 \%$ de jóvenes menciona haberla usado muchas veces, el resto la ha usado ocasionalmente y alrededor de un $36 \%$ nunca la ha usado. Las plataformas se pueden emplear de diferentes formas, y en esta muestra la proporción de jóvenes que la usan para expresar comentarios o sentimientos que no harían en persona es del $45.1 \%$ (Tabla 1 ).

Finalmente, en la dimensión de autoeficacia un $69.2 \%$ de participantes se percibe muy capaz de proteger su privacidad y seguridad en las redes sociales, además para expresar su opinión de desacuerdo, un $48.2 \%$ se percibe autoeficaz y $42.4 \%$ totalmente autoeficaz. Además, un $71.4 \%$ de ellos se siente muy capaz de defenderse si alguien lo molesta en las redes sociales (Ver Tabla 1). 
Tabla 1

Frecuencia de respuestas por ítem en la muestra total.

\begin{tabular}{|c|c|c|c|c|c|c|c|}
\hline \multirow[b]{2}{*}{ Rol } & \multirow[b]{2}{*}{ Ítem } & \multicolumn{2}{|c|}{ Nunca } & \multicolumn{2}{|c|}{ Algunas veces } & \multicolumn{2}{|c|}{ Muchas veces } \\
\hline & & $N$ & $\%$ & $N$ & $\%$ & $N$ & $\%$ \\
\hline \multirow[t]{2}{*}{ Testigo } & $\begin{array}{l}\text { Ser testigo de que los amigos/as se burlan o molestan a otros } \\
\text { compañeros/as }\end{array}$ & 259 & 15.4 & 1055 & 63.1 & 359 & 21.5 \\
\hline & $\begin{array}{l}\text { Ser testigo de que los amigos/as utilizan las plataformas } \\
\text { sociales, para burlarse o molestar a otros compañeros/as }\end{array}$ & 634 & 37.9 & 656 & 39.2 & 383 & 22.9 \\
\hline \multirow[t]{2}{*}{ Víctima } & $\begin{array}{l}\text { Ser víctima de burlas o de molestias por la apariencia física, } \\
\text { creencias o preferencia sexual }\end{array}$ & 711 & 42.5 & 785 & 46.9 & 177 & 10.6 \\
\hline & $\begin{array}{l}\text { Sentirse atacado/a por comentarios o imágenes que otras } \\
\text { personas comparten en sus plataformas sociales }\end{array}$ & 988 & 59.0 & 557 & 33.3 & 128 & 7.7 \\
\hline \multirow[t]{2}{*}{ Bullie } & $\begin{array}{l}\text { Burlarse o molestar a otros por su apariencia física, creencias } \\
\text { o preferencias sexuales }\end{array}$ & 817 & 48.8 & 701 & 41.9 & 155 & 9.3 \\
\hline & $\begin{array}{l}\text { Subir imágenes o hacer comentarios para burlarse o molestar } \\
\text { a los compañeros en las plataformas sociales }\end{array}$ & 1132 & 67.7 & 407 & 24.3 & 134 & 8.0 \\
\hline \multirow[t]{6}{*}{ Conocimiento } & Consultas de reglas comunitarias de plataformas sociales & 529 & 31.6 & 810 & 48.4 & 334 & 20.0 \\
\hline & $\begin{array}{l}\text { Utilización de configuración y herramientas de privacidad en } \\
\text { plataformas sociales }\end{array}$ & 218 & 13.0 & 811 & 48.5 & 644 & 38.5 \\
\hline & $\begin{array}{l}\text { Obtención de información de prevención del bullying en } \\
\text { plataformas sociales }\end{array}$ & 542 & 32.4 & 875 & 52.3 & 256 & 15.3 \\
\hline & $\begin{array}{l}\text { Reporte de publicaciones que son ofensivas en las } \\
\text { plataformas sociales }\end{array}$ & 842 & 50.3 & 560 & 33.5 & 271 & 16.2 \\
\hline & $\begin{array}{l}\text { Obtención de información en la Comunidad de Ayuda de tus } \\
\text { plataformas sociales }\end{array}$ & 608 & 36.3 & 752 & 44.9 & 313 & 18.7 \\
\hline & $\begin{array}{l}\text { Uso de plataformas sociales para expresar comentarios o } \\
\text { sentimientos que no se hace en persona }\end{array}$ & 422 & 25.2 & 497 & 29.7 & 754 & 45.1 \\
\hline \multirow[t]{3}{*}{ Autoeficacia } & $\begin{array}{l}\text { Protección de la información privada y seguridad en las redes } \\
\text { sociales propias }\end{array}$ & 63 & 3.8 & 452 & 27.0 & 1158 & 69.2 \\
\hline & $\begin{array}{l}\text { Expresión de la propia opinión cuando se está en desacuerdo } \\
\text { con lo que publican otras personas en las redes sociales }\end{array}$ & 157 & 9.4 & 806 & 48.2 & 710 & 42.4 \\
\hline & Defenderse cuando otros molestan en las redes sociales & 100 & 6.0 & 379 & 22.7 & 1194 & 71.4 \\
\hline
\end{tabular}

En las viñetas que se aplicaron para identificar el tipo de respuesta ante situaciones de ciberacoso, el $55.6 \%$ de los jóvenes de la muestra general responde de forma asertiva cuando alguien les transmite un video vergonzoso de uno de sus compañeros, de tal forma que deciden no seguirlo compartiendo, el $37.7 \%$ no hace nada por detener que el video se siga compartiendo y el $6.8 \%$ decide seguir transmitiéndolo para seguirse burlando de su compañero (Ver tabla 2). En la segunda viñeta, el $75 \%$ de los jóvenes responde de manera empática con el compañero del cual circula el video en las redes sociales, un $14.2 \%$ se muestra pasivo y no hace nada por resolver la situación y un $10.8 \%$ responde de manera agresiva porque piensan que su compañero se lo merece (Tabla 2). Se constatan diferencias en las proporciones de respuestas en ambas viñetas por entidad. En la viñeta 1, los porcentajes de respuestas agresivas y pasivas son más altos en la Ciudad de México, en tanto que la proporción de respuestas asertivas es similar en ambas entidades. Para la viñeta 2, las respuestas agresivas y pasivas siguen siendo mayores en proporción en la Ciudad de México, pero las respuestas empáticas son mayores en el Estado de México (Tabla 2).

Tabla 2

Porcentaje y frecuencia de respuestas en las viñetas por entidad federativa.

\begin{tabular}{|c|c|c|c|c|c|c|c|c|}
\hline \multirow[b]{2}{*}{ Viñeta } & \multirow[b]{2}{*}{ Respuesta } & \multicolumn{2}{|c|}{ General } & \multicolumn{2}{|c|}{ CIUDAD DE MÉXICO } & \multicolumn{2}{|c|}{ ESTADO DE MÉXICO } & \multirow[b]{2}{*}{$x^{2}$} \\
\hline & & $N$ & $\%$ & $N$ & $\%$ & $N$ & $\%$ & \\
\hline \multirow[t]{3}{*}{1} & Asertivo & 930 & 55.6 & 465 & 53.9 & 465 & 57.3 & $6.66^{*}$ \\
\hline & Pasivo & 630 & 37.7 & 326 & 37.8 & 304 & 37.5 & \\
\hline & Agresivo & 113 & 6.8 & 71 & 8.2 & 42 & 5.2 & \\
\hline \multirow[t]{3}{*}{2} & Empático & 1255 & 75 & 614 & 71.2 & 641 & 79 & $13.60^{\star \star}$ \\
\hline & Pasivo & 238 & 14.2 & 141 & 16.4 & 97 & 12 & \\
\hline & Agresivo & 180 & 10.8 & 107 & 12.4 & 73 & 9 & \\
\hline
\end{tabular}

Al comparar las frecuencias por entidad federativa, se puede señalar que en la mayoría de los ítems se encuentran diferencias por la entidad federativa, en los ítems referentes al rol de testigo, las frecuencias esperadas son más bajas en la categoría de muchas veces en el Estado de México, lo mismo sucede con el rol de víctima y el de bullie. Estos resultados indican que existen menos casos de jóvenes que reportan ser víctimas y bullies en el Estado de México (Tabla 3). 
En los dos primeros ítems de la dimensión de conocimiento, referentes a la consulta de las reglas comunitarias y el uso de la configuración de privacidad en las redes sociales, los jóvenes de ambas entidades reportan frecuencias similares. Las diferencias se observan en los jóvenes de la Ciudad de México: han obtenido más información sobre el bullying, han reportado con mayor frecuencia las publicaciones ofensivas, han obtenido mayor información de la comunidad de ayuda, y también son los jóvenes de la Ciudad de México quienes reportan mayor uso de las plataformas sociales para expresar sus comentarios o sentimientos (Tabla 3 ).

Por último, en relación con autoeficacia para el manejo de la privacidad y seguridad en las redes sociales, los jóvenes de la Ciudad de México se perciben más autoeficaces respecto a la protección de información, al igual que en la expresión de sus opiniones y en defenderse cuando los molestan (Tabla 3).

Tabla 3

Porcentaje por ítem y entidad federativa.

\begin{tabular}{|c|c|c|c|c|c|c|c|c|c|}
\hline \multirow[b]{2}{*}{ Rol } & \multirow[b]{2}{*}{ Ítems } & \multicolumn{3}{|c|}{ Ciudad de México } & \multicolumn{3}{|c|}{ Estado de México } & \multirow[b]{2}{*}{$x^{2}$} & \multirow[b]{2}{*}{$p$} \\
\hline & & 1 & 2 & 3 & 1 & 2 & 3 & & \\
\hline \multirow[t]{2}{*}{ Testigo } & $\begin{array}{l}\text { Ser testigo de que los amigos/as se burlan o molestan } \\
\text { a otros compañeros/as }\end{array}$ & 15.7 & 59.7 & 24.6 & 15.3 & 66.6 & 18.1 & 11.28 & .004 \\
\hline & $\begin{array}{l}\text { Ser testigo de que los amigos/as utilizan las } \\
\text { plataformas sociales, para burlarse o molestar a otros } \\
\text { compañeros/as }\end{array}$ & 33.4 & 40.3 & 26.3 & 42.7 & 38.1 & 19.2 & 19.13 & $<.001$ \\
\hline \multirow[t]{2}{*}{ Víctima } & $\begin{array}{l}\text { Ser víctima de burlas o de molestias por la apariencia } \\
\text { física, creencias o preferencia sexual }\end{array}$ & 37.2 & 47.7 & 15.1 & 48.1 & 46.1 & 5.8 & 45.85 & $<.001$ \\
\hline & $\begin{array}{l}\text { Sentirse atacado/a por comentarios o imágenes que } \\
\text { otras personas comparten en sus plataformas sociales }\end{array}$ & 50.9 & 37.2 & 11.9 & 67.7 & 29.2 & 3.1 & 70.66 & $<.001$ \\
\hline \multirow[t]{2}{*}{ Bullie } & $\begin{array}{l}\text { Burlarse o molestar a otros por su apariencia física, } \\
\text { creencias o preferencias sexuales }\end{array}$ & 42.0 & 43.6 & 14.4 & 56.1 & 40.1 & 3.8 & 65.61 & $<.001$ \\
\hline & $\begin{array}{l}\text { Subir imágenes o hacer comentarios para burlarse } 0 \\
\text { molestar a los compañeros en las plataformas sociales }\end{array}$ & 58.6 & 28.5 & 12.9 & 77.3 & 19.9 & 2.8 & 87.22 & $<.001$ \\
\hline \multirow[t]{6}{*}{ Conocimiento } & $\begin{array}{l}\text { Consultas de reglas comunitarias de plataformas } \\
\text { sociales }\end{array}$ & 30.0 & 47.7 & 22.3 & 33.3 & 49.2 & 17.5 & 6.34 & .042 \\
\hline & $\begin{array}{l}\text { Utilización de configuración y herramientas de } \\
\text { privacidad en plataformas sociales }\end{array}$ & 13.3 & 48.3 & 38.4 & 12.7 & 48.7 & 38.6 & 0.15 & .926 \\
\hline & $\begin{array}{l}\text { Obtención de información de prevención del bullying en } \\
\text { plataformas sociales }\end{array}$ & 28.0 & 51.9 & 20.1 & 37.1 & 52.8 & 10.1 & 38.60 & $<.001$ \\
\hline & $\begin{array}{l}\text { Reporte de publicaciones que son ofensivas en las } \\
\text { plataformas sociales }\end{array}$ & 44.0 & 36.7 & 19.3 & 57.1 & 30.0 & 12.9 & 30.36 & $<.001$ \\
\hline & $\begin{array}{l}\text { Obtención de información en la Comunidad de Ayuda } \\
\text { de tus plataformas sociales }\end{array}$ & 31.2 & 47.3 & 21.5 & 41.8 & 42.4 & 15.8 & 22.35 & $<.001$ \\
\hline & $\begin{array}{l}\text { Uso de plataformas sociales para expresar comentarios } \\
\text { o sentimientos que no se hace en persona }\end{array}$ & 21.7 & 33.4 & 44.9 & 29.0 & 25.7 & 45.3 & 17.01 & $<.001$ \\
\hline \multirow[t]{3}{*}{ Autoeficacia } & $\begin{array}{l}\text { Protección de la información privada y seguridad en las } \\
\text { redes sociales propias }\end{array}$ & 5.5 & 28.1 & 66.4 & 1.8 & 25.9 & 72.3 & 18.18 & $<.001$ \\
\hline & $\begin{array}{l}\text { Expresión de la propia opinión cuando se está en } \\
\text { desacuerdo con lo que publican otras personas en las } \\
\text { redes sociales }\end{array}$ & 10.0 & 45.1 & 44.9 & 8.8 & 51.4 & 39.8 & 6.63 & .036 \\
\hline & $\begin{array}{l}\text { Defenderse cuando otros molestan en las redes } \\
\text { sociales }\end{array}$ & 6.8 & 24.9 & 68.3 & 5.2 & 20.2 & 74.6 & 8.09 & .018 \\
\hline
\end{tabular}

Nota. 1: nunca, 2: algunas veces; 3: muchas veces.

\section{Discusión}

El objetivo de esta investigación fue identificar las diferencias entre los participantes del Estado de México y la Ciudad de México respecto a cuatro principales situaciones: 1) frecuencia de ciberacoso; 2) autoeficacia; 3) conocimientos sobre el uso de las redes sociales; y 4) empatía y asertividad en situaciones de ciberacoso.

Por un lado, la prevalencia del ciberacoso en los tres roles, testigo, víctima y bullie, en la muestra en general es baja, es decir, el porcentaje de casos que han molestado muchas veces es bajo y es similar al número de personas de quienes se han burlado. Por otro lado, se identificó que en Ciudad de México la prevalencia es mayor, tanto de estudiantes que molestan, son víctimas y testigos, lo cual coincide con los datos reportados por una encuesta realizada en México (INEGI, 2017), donde la prevalencia de ciberacoso reportada es mayor en Ciudad de México con un $16.8 \%$ en tanto que en el Estado de México es de 14.7\%. En particular, en el rol de bullie la frecuencia de la Ciudad de México es cuatro veces mayor que la encontrada en el Estado de México, lo cual indica que existen más adolescentes y jóvenes que molestan a sus compañeros usando las redes sociales.

En la autoeficacia se encontró que el Estado de México presenta valores ligeramente mayores a los de la Ciudad de México en la conducta de defenderse cuando otros los molestan, siendo estas diferencias estadísticamente significativas. Estos resultados reflejan diferencias entre ambas entidades federativas, lo que puede justificar el hecho de que los estudiantes del Estado de México presenten 
menos frecuencias de ciberacoso, interpretando esto como que los adolescentes que residen en el Estado de México inciden menos en llevar a cabo actos de hostigamiento a sus compañeros. Además, reflejan que la mayor parte de los participantes protegen su información y seguridad en redes sociales, así como que se defienden al ser molestados en estas redes.

En cuanto a los conocimientos que poseen, se observó que la Ciudad de México presenta valores mayores a los del Estado de México, lo que resulta interesante, ya que se esperaría que a mayor conocimiento acerca del uso de redes sociales se tuviera un uso responsable de las mismas, lo que no es el caso en esta investigación. Como mencionan Prieto y Carrillo (2015), el hecho de tener acceso a la herramienta no significa que se le dará el uso adecuado, al contrario, se suele usar para espiar, acosar y difundir información ofensiva.

Se constató también que no existen diferencias en la consulta de las reglas comunitarias que establecen las plataformas sociales y en el uso de la configuración de privacidad, de tal forma que en ambas entidades los jóvenes utilizan moderadamente este tipo de herramientas. En este mismo sentido, el Instituto Nacional de la Juventud de México (2018) reporta que un $63 \%$ de los jóvenes utilizan algún tipo de seguridad como el uso de perfil privado, restricción de ubicaciones y chats desconocidos, mientras que en el Estado de México no se realizan este tipo de comportamientos. Esto lleva a interpretar que los jóvenes con más conocimientos tienen poca sensibilidad respecto al ciberacoso, pues son los que reportan más conductas de este tipo, es por ello que se considera que a los jóvenes no les faltan conocimientos, sino que es necesario que se les sensibilice respecto al poder que tienen las redes sociales, para que de esta manera les den un uso adecuado y provechoso.

Tejada et al. (2019) identificaron que el uso de redes sociales comienza a temprana edad, por lo que pocos jóvenes reciben una orientación del uso adecuado de estas y se ven orillados a usarlas conforme las van descubriendo, es decir, por medio de ensayo y error, teniendo únicamente como referencia personas cercanas a ellos como pueden ser hermanos, amigos o padres de familia. Estas personas, igualmente, tienen escaso conocimiento del uso adecuado de las redes sociales, provocando así una réplica del uso que los mayores le están dando, no necesariamente de forma responsable e informada, y no considerando que el hecho de ser parte de una plataforma digital conlleva estar expuesto a un riesgo.

Se identificó que un mayor porcentaje de alumnos del Estado de México son asertivos en comparación a los de la Ciudad de México, lo que se corrobora en las respuestas agresivas donde el mayor porcentaje lo presentaron los jóvenes de la ciudad. Estos resultados se dieron de manera similar en las respuestas empáticas donde los porcentajes fueron mayores en el Estado de México, así como los porcentajes de las respuestas agresivas que fueron menores en el Estado que en la Ciudad de México. Precisamente en el artículo de Castellanos et al. (2016), los alumnos de la Ciudad de México identificados como víctimas-agresoras solían repetir el ciclo de violencia que experimentaban, es decir, al ser molestados buscaban venganza y molestaban a alguien más, provocando que la violencia no disminuyera.

En resumen, existen mayores frecuencias de ciberacoso en la Ciudad de México, donde parecen contestar de manera agresiva y poco autoeficaces en comparación con el Estado de México, evidenciando la necesidad de diseñar estrategias de prevención y disminución del ciberacoso. La presente investigación aporta indicadores que deben ser contemplados en los programas de intervención, como los realizados en países como Canadá, Estados Unidos, Finlandia entre otros, en donde existen leyes funcionando contra el ciberacoso, pues este fenómeno ya es considerado como un problema de salud pública que necesita ser atendido, implementando así estrategias presenciales y en línea dirigidas a las diferentes poblaciones como lo son los jóvenes, los padres de familia y el personal de las instituciones educativas, promoviendo la sensibilización al problema y la prevención de víctimas (Espelage \& Hung, 2016).

Finalmente esta investigación fue un punto de partida en la comparación entre dos entidades federativas que se encuentran en constante choque respecto a avances e implementación de programas y leyes, por ello presenta algunas limitantes que complicaron llevar a cabo la investigación. Una de ellas es la escasa evidencia empírica acerca del ciberacoso en ambas entidades federativas con la cual contrastar los datos, lo que puede deberse a que en México no existe una línea de estudio de manera federal que recabe estadísticas de manera constante acerca de la prevalencia del ciberacoso en el país. Por otra parte, en la cuestión metodológica se identifica que la encuesta empleada se puede complementar para obtener datos más precisos sobre el tipo de conductas de ciberacoso, qué tipo de red social emplean más y qué emociones experimentan al ser molestados. En conclusión, una aportación del estudio es que la muestra es amplia y permite tener un panorama de cómo se comportan los jóvenes respecto al ciberacoso en las dos entidades de nuestro país con gran relevancia. 


\section{Referencias}

1. Arab, E., \& Díaz, A. (2014). Impacto de las redes sociales e internet en la adolescencia: aspectos positivos y negativos. Revista médica clínica Los Condes, 26(1), 07-13. http://dx.doi.org/10.1016/j. rmclc.2014.12.001

2. Briones, H., \& Ortiz, D. (2014). Ciberbullying y su influencia en la asertividad. Tendencia en psicología, 1(1), 34-39.

3. Buelga, S., \& Pons J. (2012). Agresiones entre adolescentes a través del teléfono móvil y de internet. Psychosocial Intervention, 21(1), 91-101. https://doi.org/10.5093/in2012v21n1a2

4. Buelga, S., Iranzo B., Cava, M., \& Torralba, E. (2015). Perfil psicosocial de adolescentes agresores de ciberbullying. 30(2), 382-406. https://doi.org/10.1080/21711976.2015.1016754

5. Cardozo, G., Dubini, P., \& Lorenzino, L. (2017). Bullying y ciberbullying: Un estudio comparativo con adolescentes escolarizados. Revista Mexicana de Psicología, 34(2), 101-10

6. Castellanos, C., Villa, G., \& Gámez, G. (2016). Cyberbullying: Un problema de salud mental entre adolescentes mexicanos. Vertientes Revista especializada en ciencias de la salud. 19(1), 5-12.

7. Corrales, A., Quijano, N., \& Góngora, E. (2017). Empatía, comunicación asertiva y seguimiento de normas, un programa para desarrollar habilidades para la vida. Enseñanza e Investigación en Psicología 22(1), 58-65. Recuperado de https://www.redalyc.org/articulo.oa?id=29251161005

8. Espelage, D., \& Hung J. (2016) Cyberbullying prevention and intervention efforts: current knowledge and future directions. Canadian journal of psychiatry, 62(6), 374-380. https://doi. org/10.1177/0706743716684793

9. Espinar, E., \& González, M. J. (2009). Jóvenes en las redes sociales virtuales. Un análisis exploratorio de las diferencias de género. Feminismo/s, (14), 87-106. https://doi:10.14198/ fem.2009.14.06

10. Finkelhor, D., Jones, L., \& Mitchell, K. (2021). Teaching privacy: A flawed strategy for children's online safety. Child Abuse \& Neglect, 117, 105064. https://doi.org/https://doi.org/10.1016/j. chiabu.2021.105064

11. Garaigordobil, M. (2017). Conducta antisocial: conexión con bullying/cyberbullying y estrategias de resolución de conflictos. Psychosocial Intervention, 26(1), 47-54. https://doi:10.1016/j. psi.2015.12.002

12. Garaigordobil, M., \& Aliri, J. (2013). Ciberacoso (“Cyberbullying”) en el país Vasco: diferencias de sexo en víctimas, agresores y observadores. Psicología conductual, 21(3), 461-474.

13. García-Maldonado, G., Joffre-Velázquez, V. M., Martínez-Salazar, G. J., \& Llanes-Castillo, A. (2011). Ciberbullying: forma virtual de intimidación escolar. Revista Colombiana de Psiquiatría, 40(1), 115-130. https://doi.org/https://doi.org/10.1016/S0034-7450(14)60108-6

14. Hernández, R., Fernández, C., \& Baptista, P. (2010). Metodología de la investigación. McGrawHill

15. Instituto de la Juventud de la Ciudad de México. (2018). Encuesta de tendencias juveniles. [Conjunto de datos] https://www.injuve.CiudaddeMéxico.gob.mx/storage/app/uploads/public/5c8/eab/ e5b/5c8eabe5b9ef297714358.pdf

16. Instituto Nacional de Estadística y Geografía (2018). Encuesta Nacional sobre Disponibilidad y Uso de Tecnologías de la Información en los Hogares. [Conjunto de datos] https://www.inegi.org. $\mathrm{mx} /$ programas/dutih/2018/

17. Instituto Nacional de Estadística y Geografía. (2017). Módulo sobre ciberacoso MOCIBA. [Conjunto de datos]. https://www.inegi.org.mx/programas/mociba/2017/

18. Lee, W.Y., Tan, C., \& Siah, P. (2017). The role of online privacy concern as a mediator between internet self-efficacy and online technical protection privacy behavior. Sains Humanika, 9(3), 37-43. https://doi:10.11113/sh.v9n3-2.1271

19. Li, Q. (2008). A cross-cultural comparison of adolescents experience related to cyberbullying. Educational Research, 50, 223-234. https://doi:10.1080/00131880802309333

20. Livingstone, S., Stoilova, M., \& Kelly, A. (2016) Cyberbullying: incidence, trends and consequences. En United Nations, Ending the torment: Tackling bullying from the schoolyard to cyberspace. (pp. 115-120). United Nations Publications.

21. Oliveros, M., Amemiya, I., Condorimay, Y., Oliveros, R., Barrientos, A., \& Rivas, B. (2012). Ciberbullying - Nueva tecnología electrónica al servicio del acoso escolar en alumnos de dos distritos de Lima, Perú. Anales de la Facultad de Medicina, 73(1),13-18. https://doi:10.15381/anales. v73i1.804

22. Organization for Economic Co-operation and Development. (2015). Results from PISA 2015 students' well-being. [Conjunto de datos]. https://www.oecd.org/pisa/PISA2015-Students-Wellbeing-Country-note-Mexico.pdf 
23. Patchin J., \& Hinduja S. (2006). Bullies move beyond the schoolyard: a preliminary look at cyberbullying. Youth violence and juvenile justice, 4(2), 148-169. https://doi:10.1177/1541204006286288

24. Prieto, M., \& Carrillo J. (2015). Violencia virtual y acoso escolar entre estudiantes universitarios: el lado oscuro de las redes sociales. Revista Innovación Educativa, 15(68), 33-47.

25. Tejada, E., Castaño, C., \& Romero, A. (2019). Los hábitos de uso en las redes sociales de los preadolescentes. Revista Iberoamericana de Educación a Distancia. 22(2), 119-133. https://doi. org/10.5944/ried.22.2.23245

RECIBIDO: 15 de octubre de 2020 MODIFICADO: 20 de mayo de 2021 ACEPTADO: 25 de mayo de 2021 